\title{
Art Education as Folding and Unfolding of Things
}

\author{
Kayoko Komatsu \\ Correspondence: Kayoko Komatsu, Tokyo University of the Arts, Department of Art Education, Faculty of Fine Arts, \\ Associate Professor, Japan.
}

Received: July 2, 2017

Accepted: July 11, 2017

Online Published: July 14, 2017

doi:10.11114/jets.v5i8.2520

URL: https://doi.org/10.11114/jets.v5i8.2520

\begin{abstract}
This paper pays attention to the meaning of things in educational space. Students learn not only from words but also things with which they interact in the learning process. Especially in art education various things such as materials, tools, art works are indispensable. This paper tries to analyze the process of both creation and appreciation of art in the viewpoint of folding and unfolding of things. The methodology is the hermeneutic approach to the relationship between art works and viewers, materials or tools and their users, and created image and creators. In creating art works the process of unfolding things which means the interaction with materials and the learning of skills and tools can emerge only by folding the image of the creator into the things. On the other hand, it is important for appreciation to receive the image of art works by developing it freely in the inner world. As in the case of creation, appreciation needs both folding a new meaning and unfolding the multilayered art works. In conclusion both creation and appreciation of art are so complicated processes that need a high degree of intelligence. Art education can be regarded as the process of fostering intelligence as well as sensibility.
\end{abstract}

Keywords: art education, things, gaze, image, metaphor

\section{Introduction}

This paper is a part of the research project concerning about 'Things and Media in Educational Space'. The research group consists of five researchers who specialize in philosophy of education. The methodology of our project is hermeneutic approach to the meaning of things in educational space. These two years collaborating with Museum of Contemporary Art Tokyo and two primary schools, we examined the transitions from appreciation to creation by observing the process of appreciation and creation of art works of 106 pupils. They appreciated several contemporary art works made of paper in that Museum and made their own works using paper after coming back to their classrooms. We observed how children produced their own art works inspired by things such as art works in the museum and materials in the classroom. Each member of our project has analyzed this practice from their own viewpoints. Because of the specialty of us the way of our research is the qualitative interpretation of the practice rather than the description of it.

I have paid attention to the process of creation and appreciation of children and managed to capture the phenomenon occurred in that process. My viewpoint is folding and unfolding of things which are operating in both creating process of children and those of professional artists. In addition to it I try to analyze the appreciation of art works in the same way as art creation. Different from words the meaning of things cannot be fixed because they have multilayered aspects and the meaning of things comes into existence through the interaction between things and human beings. The interaction with the multilayered things gives us the intelligence of connecting the inner image and outer things. Through these examinations the characteristic of art education will be clarified, especially the aspect of fostering a high degree of intelligence.

\section{Things in Art Creation}

The creation of art works includes both the aspect of interacting with materials and producing them into works through the use of tools and skills. In the Japanese primary school, the interaction with materials is adopted as a sphere of the curriculum of art education, which is called 'Zokei Asobi' (plastic activity through playing). Artists also think carefully about the materials and interact with them before producing art works. Making the best use of them, they are inspired by the materials and respond to them. Such an attitude reflects, as it were, 'love for the materials' (an expression used by an art university student) or being 'true to the material' (Ingold, 2007, p.13). 
Things in art creation are not just materials. In producing art works, especially in the case of craft works, tools are important. Tools have folded within themselves the long and continuous history of techniques. Acquiring a mastery of the use of tools requires the unfolding of the techniques folded into the tools for a while and folding them again in conformity with its user's body and the purpose of creation. The idea of 'folding' is dependent on an article by Hiromoto Makabe who is a member of our research project. Having been inspired by the book of Horst Bredekamp on Leibniz, he said as follows. "Children who make up the next generation, as it were, should learn the "cultural skill of symbols' to unfold the object and language which fold an established meaning." "Bildung alternates between the process of acquiring 'the cultural skill of symbols,' which makes the structure or style, and that of interrupting the structure, which makes it into fragments or deconstructs it. That is the process of inscribing pleats or folds in both the outer and inner world" (Makabe, 2016, pp.151-152).

Art works cannot be created only by learning the method of folding through the unfolding of things. The key point in the creation of art works is not only the acquiring of the way to use tools and skills but also the involvement of the creator. Tim Ingold opposes the Actor Network Theory (ANT), which distributes the agencies in the relational network between human beings and things (cf. Law \& Hassard, 1999). Depending on James Gibson's theory of visual perception, Ingold emphasizes the development of skills achieved by an organic body through its own perception in the environment. He set SPIDER (Skilled Practice Involves Developmentally Embodied Responsiveness) against ANT. When the educational meaning of things is thought about, the consideration of the interaction between things and human beings is essential. Even if things inspire us, it is the relationship between things and us that renders such a function of things practicable. "Things can have meanings that may transform the very world in which we live. But things by themselves alone cannot help us; only in the way we relate to them is their symbolic energy released"(Csikszentmihalyi \& Rochberg-Halton, 1981, p. 247). "When I bring a Visual Culture Art Education approach into (arts) education, the focus of my interest is not about 'what' (objects, images), or 'how' (the ways we interpret what we see), but about the space where what we gaze at, and how we are seen by what we gaze at, becomes a place to meet and interact" (Hernández, 2015, p.193).

In the next section, I would like to think about the interaction between things and us from the viewpoint of the gaze.

\section{From Things to Gaze}

In the project collaborating with Museum of Contemporary Art Tokyo, we examined the transitions from appreciation to creation in primary school pupils. We observed how children produced their own art works inspired by things such as art works in the museum and materials in the classroom. Even when they saw the same works and used the same materials, the works made by them were different from each other. This difference is supposed to be caused by the different image they conceived when they saw the things. However, it is difficult to capture the image because it is not directly presented in the drawings or works. The image can only appear through some media. The "presence of an absence" is the intrinsic quality of the image. Hans Belting, relying on the work of Régis Debray, describes this issue as follows. "In order to cope with the intangible nature of the mental image, Debray introduces the gaze in its place, for he considers the gaze as the vector for transmitting mental images to material picture and back" (Belting, 2011, p.4). It is the gaze that connects the invisible image and picture in the real world.

The gaze is discussed in the research area of Bildwissenschaft (science of picture or image). Recently a lot of monographs have been published in this area, including a reappraisal of Aby Moritz Warburg, who opposed the style-based research of art history. This may be related to the 'imaginal turn of philosophy' (Okada, 2014). Bildwissenschaft encompasses a wide range from the practice of image in the natural science to the image in the prehistoric times using the method of experimental science. This paper cannot trace all this vast research, but will instead consider the gaze from the viewpoint of art education, focusing on its relation to the multilayered nature of things.

Referring to Belting, Christoph Wulf explains the gaze as follows. "The gaze is active as well as passive; it turns outward to the world and at the same time receives it." "The gaze is going back and forth among image, body, and media. It does neither stay in the body nor in the image, but develops in the medial area" (Wulf, 2009, p.131).

The gaze, which is active as well as passive, and develops 'in-between' image and body, generates mimesis and promotes our transformation. It is by the gaze regarding an image and things in layers that we can be inspired by things and fold the layers of image into things. The image itself cannot be directly captured, but it can be only presented through some media. Things in art emerge both as media representing some image and as materials in themselves. Thus, it can be described as 'semitransparent' media to borrow the term used by Atsushi Okada (Okada, 2014, p.21). Art works bring to us this multilayered meaning through such semitransparent media.

An image can only be presented through some media. Considering the case of a copy makes this to be understood well. A copy never can be established just by tracing the image. The work of Leila Pazooki in the exhibition of Lucas 
Cranach at The National Museum of Western Art in Japan, which was held in 2016, indicates it. The title of the work is 'A Printing Competition of Allegory of Justice by Lucas Cranach the Elder 1537.' Pazooki asked the one hundred painters in an artist village in China, where over half of the reproduction of paintings in the world are produced, to copy 'Allegory of Justice' of Cranach in six hours. The video recording the copying process and the 100 reproductions were exhibited. When I saw that 100 pictures, I was deeply impressed that nobody can become Cranach even if they trace the image. The image cannot be separated from the medium. The work of Pazooki showed this self-evident and unquestionable truth.

This is thought to be very important when thinking about the problem of art education. Those who come to dislike making art often say that they cannot create their work as imagined. Although they have an ambiguous image, they cannot represent it because of a lack of the skill. This lack of skill disturbs the clarification of image, which results in a vicious spiral. So, is it the most important in art education to teach skills thoroughly? However, skills are "the operation which brings forth both 'idea' and 'things' at the same time in the process of creation" (Morita, 2013, p. 104). Skills cannot be taught separately from making the creator's idea into art work. The inseparability of image from media is an essential aspect of art, which causes the difficulty in art education. To overcome this problem, the gaze should be paid attention to, because it is through "the animating gaze" that "we transform pictures in the eternal world into images" (Belting, p.45).

\section{The Creation of Image by Gaze}

The Works of Yasumasa Morimura 'Mother (Judith I)' at the same exhibition of Cranach was interesting for us to think about in terms of the animating gaze. He copied the image of 'Judith with the Head of Holofernes' of Cranach. In this work the medium is Morimura himself, so that the inseparable image and medium had been separated and that separation gave a newly supposed image. Morimura's work is literally an "animating" picture. His gaze clearly expressed it. In almost all parts he was tracing faithfully the image of Cranach, but he deviated on one point; that is the gaze. He directed his gaze to us. The viewers who gaze at the work feel that they are gazed at by the animated image.

Separating image from medium questions the transparency of media and emphasizes the thingness of art works. At the same time, the animating gaze disrupts the image from being fixed and makes it develop in both individual and collective bodies.

An image cannot become an image unless captured by the gaze. The fixed image alienates us from the image and makes the appreciation of art works uninteresting. "The cultures of the past are, it would seem, migrating into books and museum, where they are archived but no longer live. They survive in documentary images (much like old places that are recalled only in photographs), but these images would themselves constitute a new death were they not once more brought to life in the museum audience" (Belting, 2011, p. 46).

It is necessary for enjoying art works to get the animating gaze, which transforms pictures into image. Understanding the image with the animating gaze brings about the 'flow' experience. This does not mean decoding what the artist has encoded. Csikszentmihalryi \& Rochberg-Halton, discussing the flow experience relating to the aesthetic experience, mentioned as follows. "The aesthetic experience has usually been either reduced to a mere sensation of physiological perception or to a cultural convention. In the former case, it is seen as a hedonistic individual sensation of pleasure, whereas in the latter all meaning is purely conventional. ...Including qualitative immediacy as an element of the person-object transaction seems to offer a way to go beyond the usual argument that reduces art solely to social convention or the utilitarian argument that art only gives a 'pleasure sensation' but is not an essential aspect of social life" (Csikszentmihalryi \& Rochberg-Halton, 1981, p. 178).

Their discussion depended on the distinction between the recognition and perception of John Dewey. "Recognition is when we experience a thing and interpret it only as something we already know...Perception, on the other hand, occurs when we experience a thing and realize its own inherent character" (Csikszentmihalryi \& Rochberg-Halton, 1981, p. 44). "In perception the objective qualities of objects are intrinsic to our experience; in recognition they are extrinsic. An experience of perception means that the scheme through which we interpret an object is changed or enlarged, which is how learning occurs, by enlarging or changing the habitual framework of interpretation" (Csikszentmihalryi \& Rochberg-Halton, 1981, p.181).

Perception indeed reexamines the established scheme, through which self-transformation is made possible. That reminds us of the idea of 'event' discussed by Dennis Atkinson. Atkinson considered the "real learning arising through an event which involves a movement into a new or changed ontological state" (Atkinson, 2011, p.5-6).

The animating gaze makes the image escape from fixation and develop in the person who gazes at it. Such a development of image can be called imagination. "In art works the primary practice of image switches to the secondary practice of image. Although the image has no life, gazing it develops the imagination" (Wulf, 2009, p.31). 


\section{Creation and Appreciation of Art as Folding and Unfolding}

The animating gaze of image separates image from medium, bringing about the thingness of things and developing the image freely in the person who gazes at it. Is that the process of unfolding things that was folding some image? It is not so simple.

In creating art works, the creator's understanding of materials, skills, and tools are indispensable. The interaction with materials and the learning of skills and tools can be regarded as unfolding the ancestral wisdom folded in things. That is different from analytical understanding. It is impossible to learn materials, skills and tools isolated from creating activities. Art works can be created not only by the interaction with things but also by realizing the image into some works. The process of unfolding things can emerge only by folding the image into the things that produced the medium as well as the image. Everyone in creating art works should make the best use of the thingness of things and fold their own image into things. Therefore, despite appreciating the same thing, each work has its own individuality. That is a very complicated process and needs a high degree of intelligence. How can we learn such a complicated process by reducing a simple one? The training of drawing in the Academy of Fine Arts might have been a method of learning skills, which simplified the complicated process into an analytical one (cf. Ackerman, 2007). However, in accordance with the criticism of the education of Academy, art creator's learning was individualized and the complexity, which needs a high degree of intelligence, was forgotten. Finally creating skills became to be regarded as genius and unteachable.

On the other hand, as is discussed in the latest section, it is important for appreciation to receive the image of the art works by the animating gaze and developing it freely in the inner world. The 'Re-creative viewer', which is the highest aesthetic stage of appreciation in visual thinking strategy, can develop such an imagination (Housen, 2001). Appreciation is not only aesthetic enjoyment but also something that enriches the experience folding new and different meanings into the image. Essentially, appreciation is more or less a creative action if not at the highest aesthetic stage. The social view, that is, the group appreciation of art works together with some blind persons, demonstrates this. Asa Itoh points out that what is interesting about the social view is that it is made by sharing the 'subjective meaning' rooted in the individual experience (Itoh, 2015). What the sighted persons explain is not only the objective information, such as the size or the color of the works, but also fragmentary interpretations, which are as different and changeable as each viewer's way of seeing. "The blind persons construct the art works in their brain while patching the temporary parts of information" (Itoh, 2015, p. 174). In other words, the blind persons gather the various elements of the art work unfolded by others and each time fold them into their own image. Without such a re-creative action, an image cannot emerge even if they listen to whatever amount of information.

That does not mean the viewers should appreciate art works as they like. As in the case of creation, appreciation needs both folding a new meaning and unfolding the multilayered art works. Junko Miki, who draws from the work of Gottfried Boehm, says that "the waking and skillful eyes" are necessary for the experience of painting, which is the experience of image (Bild). "The eyes should master the sensitive syntax appropriate for the image. At that time, the image presents its inner relationship and awakens the eyes to that relationship" (Miki, 2002, pp.59-60). We can unfold the meaning because we have the eyes that can fold the meaning.

The special characteristic of art is that it can both fold into things and unfold the things at the same time. Art education can be regarded as the process of learning this.

\section{Art Education for Fostering the Gaze}

Ernest Grassi saw the following two elements of metaphor indispensable for art works. "Art works", said he, "originate from the transition of the image that artists conceive in their inner world into the material." On the other hand, they originate from "reducing the materials into the image and projecting them to the inside of the creators" (Grassi, 1970, p. 173). Grassi does not think that "the completed conception of artists is realized", but that "although artists try to complete themselves or their conception in their work, they can make them clear only through forming the materials and ruling out some possibilities" (Grassi, 1970, pp. 173-174). It is not that initially the image has been predetermined and after that it is presented, but that the image itself is found in the process of forming the materials into the work. In other words, the image in the artist is discovered through the interaction with things. That process is realized by a metaphor. If we connect these statements with the discussion above, the 'transition of the image into the material' is the same process as folding the image into things; 'reducing the materials into the image' is the same process as separating the image from the medium and unfolding the multilayered things. The operation connecting the inner image and outer things is nothing but the gaze. Debray says, "Regarding is not to receive the visible but to order the visible and organize the experience" (Debray, 1992, p.56). Regarding the inner image and the outer things, which are both undetermined, transforms the materials to get a meaning as well as presents the outline of the inner image. Such a human formation through image (Bildung durch Bild) cannot be realized other than through art education. 
Art education gives us the intelligence that makes the inner image multilayered by examining the multilayered things. The multilayer consists of various phases behind things, such as the culture taken over as tools and skills, the experience of others folded in the art works, the concept for the art works inspired by the materials, and so on. How should we refer to the intelligence regarding the invisible in the folding and unfolding of things? Should we call it metaphorical intelligence? Or intelligence as gaze? Whatever the case, that is what makes 'artistic reflection' possible. In conclusion both creation and appreciation of art works are so complicated processes that need a high degree of intelligence. That is different from the usually understood intelligence such as linguistic or mathematical, nonetheless it is an intelligence. Art education can be regarded as the process of fostering intelligence as well as sensibility.

\section{Acknowledgements}

This work was supported by JSPS KAKENHI Grant Number $15 \mathrm{H} 03478$.

\section{References}

Ackerman, G. M. with the collaboration of Graydon P. (2007). Charles Bargue Drawing Course: with the collaboration of Jean-Léon Gérôme ( $2^{\text {nd }}$ ed.). Paris: ACR Edition.

Atkinson, D. (2011). Art, Equality and Learning: Pedagogies against the State. Rotterdam, Netherlands: Sense Publishers. https://doi.org/10.1007/978-94-6091-454-6

Belting, H. (2011). An Anthropology of Images: Picture, Medium, Body. Princeton, NJ: Princeton University Press.

Csikszentmihalryi, M., \& Rochberg-Halton, E. (1981). The Meaning of Things, Domestic Symbols and the Self. Cambridge, UK: Cambridge University Press. https://doi.org/10.1017/CBO9781139167611

Debray, R. (1992). Vie et mort de l'image: Une historie du regard en Occident. Paris: Gallimard.

Grassi, E. (1970). Macht des Bildes: Ohnmacht der rationalen Sprache. Köln: DuMont.

Hernández, F. (2015). Promoting Visual Culture Art Education Learning Experiences as a Pedagogical Event, in; Mallio-Tavin, M. \& Pullinen, J., Conversations on Finnish Art Education (pp. 188-201). Helsinki, Finland: Aalto ARTS Books.

Housen, A. (2001). Eye of the Beholder: Research, Theory and Practice. Retrieved from https://vtshome.org/wp-content/uploads/2016/08/5Eye-of-the-Beholder.pdf

Ingold, T. (2007). Materials against Materiality, Archaeological Dialogues, 14(1), 1-16. https://doi.org/10.1017/S1380203807002127

Ingold, T. (2015). When ANT meets Spider: Social theory for arthropods. In Knappett, C. \& Malafouris, L. (Eds.). Material Agency: Towards a Non- Anthropocentric Approach (pp.209-215). New York, NY: Springer.

Ito, A. (2015). Me no Mienai Hito wa Sekai wo Dou Miteirunoka? (How do the Blind Persons See the World?). Tokyo, Japan: Kobunsha.

Law, J., \& Hassard, J. (Eds.) (1999). Actor Network Theory and After. Oxford, UK: Blackwell.

Makabe, H. (2016). 'Aida no Sekai' no Shinri-gaku (Psychology in 'in-between world'). The Philosophy of Education Society in Japan, Studies in the philosophy of Education, 113, 151-152.

Miki, J. (2002). Keisho toiu Keiken (The Experience of Image). Tokyo, Japan: Keiso-Shobo.

Morita, A. (2013). Geijutsu no Cyudo-tai (The Middle Voice of Arts). Nara, Japan: Kizasu-Shobo.

Okada, A. (2014). Image no Kongen he (Towards the Origin of Image). Kyoto, Japan: Jinbun-Shoin.

Wulf, Ch. (2009). Image, gaze, and imagination, (translated into Japanese by Yasuo Imai). Graduate School of Education, the University of Tokyo, Bulletin of the Division of Basic Theories of Education, 35, 125-133.

\section{Copyrights}

Copyright for this article is retained by the author(s), with first publication rights granted to the journal.

This is an open-access article distributed under the terms and conditions of the Creative Commons Attribution license which permits unrestricted use, distribution, and reproduction in any medium, provided the original work is properly cited. 